\title{
From the Cochrane Library: Skin Care Interventions in Infants for Preventing Eczema and Food Allergy
}

Jarett Anderson ${ }^{1}$, BS; Torunn Sivesind ${ }^{2}$, MD

${ }^{1}$ Midwestern University, Glendale, AZ, United States

${ }^{2}$ University of Colorado School of Medicine, Aurora, CO, United States

\section{Corresponding Author:}

Jarett Anderson, BS

Midwestern University

19555 N 59th Ave

Glendale, AZ, 85308

United States

Phone: 18016567069

Email: janderson99@midwestern.edu

(JMIR Dermatol 2021;4(2):e30197) doi: 10.2196/30197

\section{KEYWORDS}

eczema; atopic dermatitis; skin care; emollients; pediatrics; food allergy; allergy; dermatology

Eczema is a common and taxing condition, with an estimated prevalence of $10.7 \%$ among pediatric patients in the United States and a cost of US \$5 billion annually [1]. Eczema has a known association with food allergies, with both conditions commonly developing during the first year of life. The cost of care and daily attention required to treat both eczema and food allergy represent significant burdens to individuals and families. Without a global standard for neonatal or infant skin care, and with few emollient studies performed in term infants, Kelleher et al's Cochrane review [2] provides a much-needed assessment of the evidence for emollients and other interventions to prevent eczema, as well as their effects on the development of food allergy.

This systematic review assessed 33 randomized controlled trials $(n=25,827)$, all of which studied term ( $>37$ weeks) infants $(<12$ months) without a pre-existing diagnosis of eczema, food allergy, or other skin condition. Clinically relevant findings are summarized in Table 1.

Table 1. Clinically relevant findings.

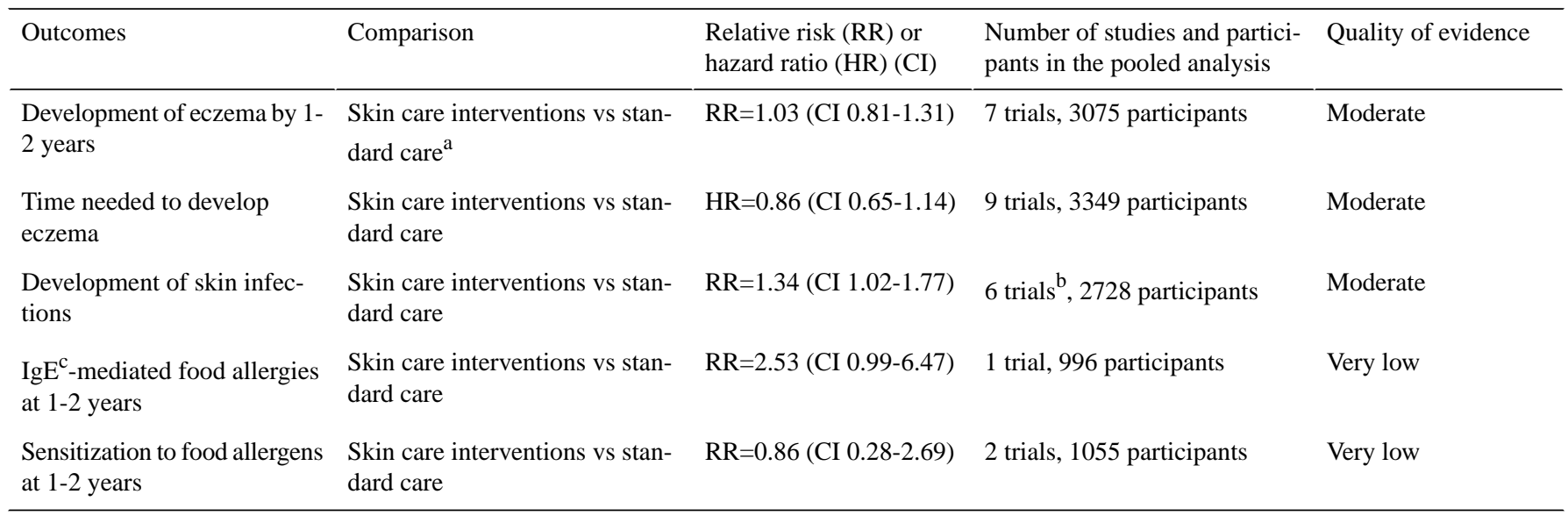

${ }^{\text {a }}$ Standard care is defined as no skin care or care as usual.

${ }^{\mathrm{b}}$ While 2 out of the 6 studies in the pooled analysis slightly favored skin care interventions (not statistically significant), the pooled data suggested an increased risk of skin infection with emollients. The studies contributing to the pooled data varied in a number of study-related and patient-specific characteristics.

${ }^{\mathrm{c}} \mathrm{IgE}$ : immunoglobulin E. 
There was limited evidence concerning the impact of skin care interventions on IgE (immunoglobulin E)-mediated food allergies; the few trials that investigated these outcomes produced broad CIs that failed to achieve statistical significance.

An important strength of this review was its inclusion of 7 studies in a meta-analysis evaluating study-specific factors (eg, type of emollient, duration) and participant covariates (eg, age, FLG [filaggrin] genotype, family history of atopy), which revealed no interplay between these factors and the intervention on eczema risk. Other potential confounders (such as bath water composition, detergent type, diet, climate and geographical factors, and dust and home allergens) were not assessed.

Further, the intervention and control groups varied widely between the included studies such that single and combination emollients of differing contents were considered together. The control (standard care) was likewise variable, depending upon national standards and cultural norms. These limitations highlight the need for additional research to improve the generalizability of the results to diverse populations.

Efforts to identify the effects of different skin care interventions on the prevention of eczema and their effects on food allergy are also warranted. There are currently a number of ongoing clinical trials assessing skin care interventions for the prevention of atopic dermatitis and food allergy; one trial recently concluded there is no evidence that the use of daily emollients reduces the risk of eczema by the age of 2 years in high-risk patients (patients with first-degree relatives with a history of eczema, asthma, or allergic rhinitis) [3].

The incidence of eczema has increased, especially since the onset of the COVID-19 pandemic. With an enhanced emphasis on frequent hand washing, hand hygiene has become an increasingly popular topic among individuals and families [4]. In recent years prior to the pandemic, an increase in the incidence of eczema in the pediatric population was reported, most prominently among infants [5]. With this in mind, it is important for clinicians to familiarize themselves with evidence-based treatment regimens, supported by data from sources like the Cochrane Library. Utilizing information from numerous studies simultaneously, as in the review summarized here, supports best practice and enables physicians to effectively counsel patients.

\section{Conflicts of Interest}

TS serves as a section editor for JMIR Dermatology. TS receives fellowship funding from the Pfizer Global Medical Grant (58858477) Dermatology Fellowship 2020 (PI: R Dellavalle) and serves on the Medical Advisory Board of Antedotum Inc. JA serves as a social media editor for Cochrane Skin.

\section{Editorial Notice}

The views expressed in this paper are those of the authors and in no way represent the Cochrane Library or Wiley.

This article is based on a Cochrane Review previously published in the Cochrane Database of Systematic Reviews 2021, Issue 2, DOI: 10.1002/14651858.CD013534.pub2 (see www.cochranelibrary.com for information). Cochrane Reviews are regularly updated as new evidence emerges and in response to feedback, and Cochrane Database of Systematic Reviews should be consulted for the most recent version of the review.

\section{References}

1. Drucker AM, Wang AR, Li WQ, Sevetson E, Block JK, Qureshi AA. The Burden of Atopic Dermatitis: Summary of a Report for the National Eczema Association. J Invest Dermatol 2017 Jan;137(1):26-30 [FREE Full text] [doi: 10.1016/j.jid.2016.07.012] [Medline: 27616422]

2. Kelleher MM, Cro S, Cornelius V, Lodrup Carlsen KC, Skjerven HO, Rehbinder EM, et al. Skin care interventions in infants for preventing eczema and food allergy. Cochrane Database Syst Rev 2021 Feb 05;2:CD013534. [doi: 10.1002/14651858.CD013534.pub2] [Medline: 33545739]

3. Chalmers JR, Haines RH, Bradshaw LE, Montgomery AA, Thomas KS, Brown SJ, et al. Daily emollient during infancy for prevention of eczema: the BEEP randomised controlled trial. The Lancet 2020 Mar;395(10228):962-972. [doi: 10.1016/S0140-6736(19)32984-8]

4. Hajar T, Simpson EL. The Rise in Atopic Dermatitis in Young Children. JAMA Netw Open 2018 Nov 02;1(7):e184205. [doi: 10.1001/jamanetworkopen.2018.4205] [Medline: 30646336]

5. Singh M, Pawar M, Bothra A, Choudhary N. Overzealous hand hygiene during the COVID 19 pandemic causing an increased incidence of hand eczema among general population. J Am Acad Dermatol 2020 Jul;83(1):e37-e41 [FREE Full text] [doi: 10.1016/j.jaad.2020.04.047] [Medline: 32305441]
Abbreviations
FLG: filaggrin
IgE: immunoglobulin E 
Edited by G Eysenbach; submitted 05.05.21; peer-reviewed by J Solomon, A Allam; comments to author 16.06.21; revised version received 25.06.21; accepted 30.07.21; published 02.09.21

Please cite as:

Anderson J, Sivesind T

From the Cochrane Library: Skin Care Interventions in Infants for Preventing Eczema and Food Allergy

JMIR Dermatol 2021;4(2):e30197

URL: https://derma.jmir.org/2021/2/e30197

doi: $10.2196 / 30197$

PMID:

CJarett Anderson, Torunn Sivesind. Originally published in JMIR Dermatology (http://derma.jmir.org), 02.09.2021. This is an open-access article distributed under the terms of the Creative Commons Attribution License (https://creativecommons.org/licenses/by/4.0/), which permits unrestricted use, distribution, and reproduction in any medium, provided the original work, first published in JMIR Dermatology Research, is properly cited. The complete bibliographic information, a link to the original publication on http://derma.jmir.org, as well as this copyright and license information must be included. 